\title{
THE MARRIAGE OF ASTRONOMY AND CULTURE: THEORY AND METHOD IN THE STUDY OF CULTURAL ASTRONOMY
}

\author{
A special issue of Culture and Cosmos \\ Vol. 21 no. 1 \\ Spring/Summer 2017
}
Copyright (C) 2017 Culture and Cosmos
All rights reserved
Published by Culture and Cosmos
\& Sophia Centre Press
England

www.cultureandcosmos.org

In association with the

Sophia Centre for the Study of Cosmology in Culture,

University of Wales Trinity Saint David,

Faculty of Humanities and the Performing Arts

Lampeter, Ceredigion, Wales, SA48 7ED, UK

British Library Cataloguing in Publication Data

A catalogue card for this book is available from the British Library

All rights reserved. No part of this book may be reproduced or utilized in any form or by any means, electronic or mechanical, including photocopying, recording or by any information storage and retrieval system, without permission in writing from the Publishers.

ISSN 1368-6534

Printed in Great Britain by Lightning Source 


\section{CULTURE AND COSMOS}

www.CultureAndCosmos.org

Editor: Nicholas Campion

Guest Editors: Liz Henty, Bernadette Brady, Darrelyn Gunzburg, Frank Prendergast and Fabio Silva

Vol. 21 No. 1 Spring/Summer 2017

ISSN 1368-6534

Published in Association with

The Sophia Centre for the Study of Culture in Cosmology,

Faculty of Humanities and the Performing Arts

University of Wales Trinity Saint David

http://www.uwtsd.ac.uk/sophia/

\section{Editorial}

This volume of Culture and Cosmos draws together a selection of papers delivered at the $24^{\text {th }}$ annual conference of the European Society for Astronomy in Culture (SEAC). Titled 'The Marriage of Astronomy and Culture: Theory and Method in the Study of Cultural Astronomy', the meeting occurred between the $12^{\text {th }}$ and the $16^{\text {th }}$ September 2016 and was held at The Bath Literary and Scientific Institution (BRLSI), which has been hosting research endeavours since it foundation in 1824. BRLSI is now located in Queens Square, which was designed by John Wood in c.1728, the architect who also planned the famous Bath Circle. With its medieval abbey, restored in the seventeenth century, and Roman Baths close by, Bath is therefore full of archaeological interest. It also has archaeoastronomical significance because Wood believed that the seven hills of Bath were dedicated to the heavenly bodies. ${ }^{1}$ He drew a planetary model overlaid onto plans of the monuments near Stonehenge so that for him Silbury was the hill of Mars and Stonehenge was an oracular lunar temple of the moon. With conference tours to Stonehenge, Avebury and Bath Abbey we could really believe we were 'standing on the shoulders of giants'.

${ }^{1}$ John Michell, [1977] A Little History of Astro-Archaeology: Stages in the Transformation of a Heresy (New York: Thames \& Hudson Inc., 1989), p. 12. 
SEAC 2016 combined history with the latest in twenty-first century developments and, for the very first time, was webcast to SEAC members who could not attend, in addition to students of the MA in Cultural Astronomy and Astrology. In total, twenty-five people took advantage of this facility and were able to engage in the live sessions and also ask questions of the speakers. The sessions were webcast and recorded using Cisco WebEx and held on the Sophia Centre's server for a few weeks to allow delegates to access the recordings after the conference. Delegates who registered for the online webcasts could choose fees varying from $£ 25$ for a half-day session to $£ 120$ for the full conference. Apart from allowing a wider audience to partake of the many excellent lectures given, the physical presence of around 90 delegates was boosted by these online attendees. The opening address and welcome speech for the five day conference was given by SEAC President Michael Rappenglück. This was followed with a presentation by Nicholas Campion of the Sophia Centre for the Study of Cosmology in Culture (University of Wales Trinity Saint David). He considered the state of cultural astronomy today and how it has moved on from Lockyer's early twentieth century speculations and the 1960s' controversial publications of Gerald Hawkins and Alexander Thom who brought the field to the public's attention. For many years the key role of the SEAC conferences has been the promotion of archaeoastronomy and cultural astronomy research, yet its research papers only tend to reach a limited audience. From this pioneering effort archaeoastronomy has developed in Britain and in the last few years has found a place in academia with the Sophia Centre's MA in Cultural Astronomy and Astrology which introduced a dedicated archaeoastronomy module in 2010. Skyscapes sessions at the Theoretical Archaeology Group conferences, the National Astronomy Meetings and the new Journal of Skyscape Archaeology have built upon this impetus.

\section{Conference highlights}

The conference offered an innovative programme, so in addition to the many research papers, a 'Skills' session, specifically dedicated to developing the skill sets of all attendants, was trialled. There were three presentations in this session focusing on different technical aspects. Frank Prendergast covered the basics of coordinate reference systems, map projections and coordinate conversion. Victor Reijs, whose presentation is freely available online (http://tinyurl.com/j8myvfb), spoke of virtual fieldwork tools, as well as common smartphone and tablet survey apps, especially highlighting their pitfalls. Finally, Georg Zotti, elaborated on 
new Stellarium functionalities that include the import of Digital Terrain Models and/or 3D models of structures for accurate simulation of the natural and built environments. Altogether, we believe this was a very successful session, new to SEAC, with a didactic tone, but focussing on skills that are new and of use to even the most weathered cultural astronomer.

Following the lecture presentations, a Round Table Forum was held to discuss the key themes that could be used to define the discipline of cultural astronomy. A mind map, projected onto the presentation screen, was interactively built as the discussion developed. Debates surged around methodologies, as well as on some of the problems encountered within the scholarship of cultural astronomy and how the subject was perceived both by other scholars and the general public.

The ensuing mind map (Fig.1) shows the five commonly agreed points concerning cultural astronomy directly linked to the central topic. The delegates considered that cultural astronomy covers such disciplines as anthropology, astronomy, archaeology, history, art history, and religious studies and, consequently, that it requires an engagement with its primary sources using both qualitative and quantitative research techniques. Importantly it was recognised that scholars often needed to reach beyond an individual discipline and adopt a trans-disciplinary approach, collaborating with others, sharing resources, and integrating other methodologies into how primary sources were handled. Finally, the issue of recognition and acceptance of cultural astronomy as its own field by other academic fields, as well as by general society, was also discussed and regarded as being of primary importance to ensure the survival of the discipline.

Ancillary topics, also debated, are shown as orange boxes in Fig. 1. These focused on the practical approach to engaging in the study of cultural astronomy. Primarily it was acknowledged that there was a need to consider alternate ontologies, while, at the same time in terms of field work based studies, there was a strong need to engage physically in the landscape and skyscape. Finally, the problems of presenting such a transdisciplinary subject to the wider social and academic communities, the usual clash between those trained in the humanities and the natural sciences, as well as the isolation of the cultural astronomy community were also debated. The resulting mind map is a record of one stage of this discussion among SEAC 2016 attendees. It is hoped that this map can form the basis for future discussions and will be revisited, updated, and developed over the coming years. 


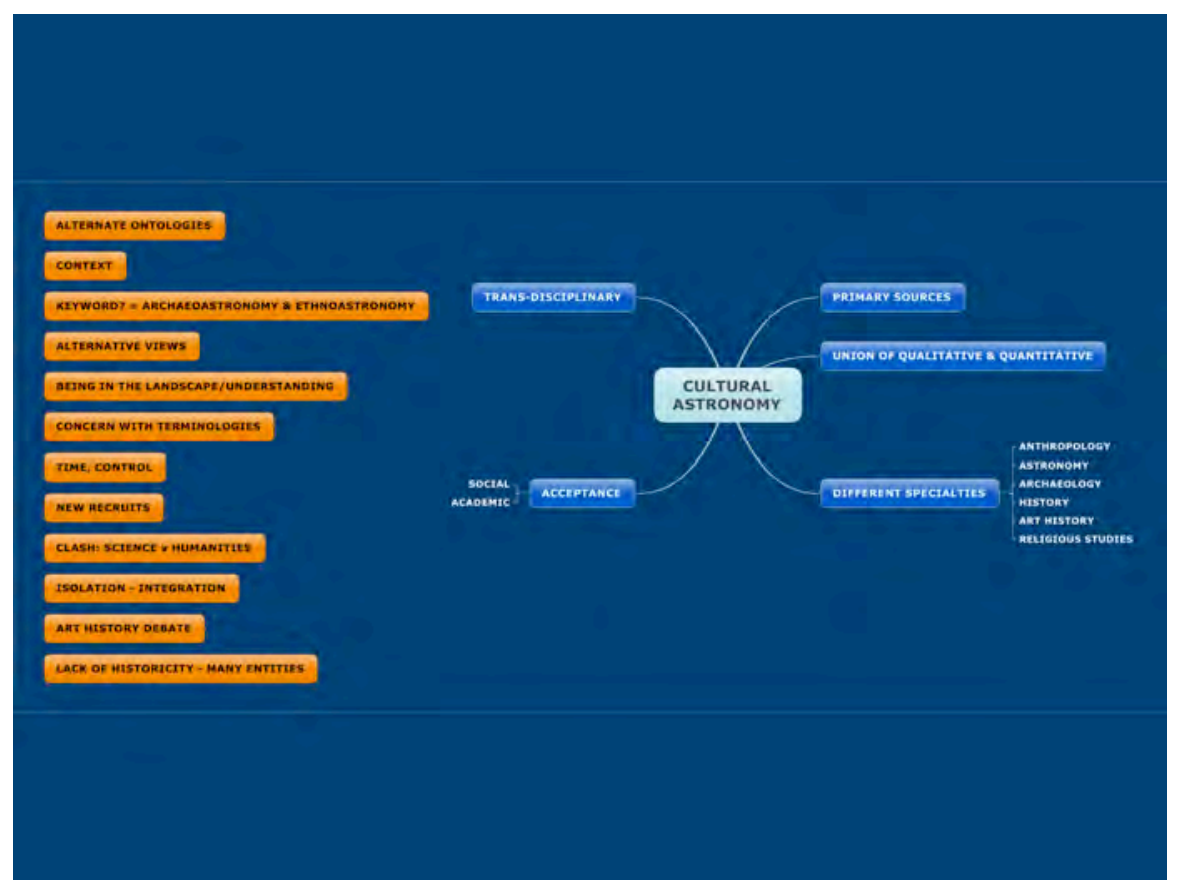

Fig. 1. The Mind Map composed by the delegates of SEAC2016, Bath, UK.

The well-attended public lecture, 'Exploring the Monuments and Cosmology of the Boyne Valley. What's the Bigger Picture?', was given by Frank Prendergast. He explored how, by about 3200 BCE, organised communities were farming in the Boyne Valley and constructing enormous burial chambers. These have yielded characteristic grave goods, with many of the structural stones being embellished with elaborate incised art. Their siting and axial orientations are believed to reflect societal concerns with hierarchy, religious beliefs and cosmology. Understanding these monuments may give insights in a regional and broader European context.

SEAC conferences, which are held in a different European city each year, make the most of the local attractions for socialising and tours. On Monday evening the University of Wales Trinity Saint David hosted a 'Wine and Nibbles' event at the Herschel Museum of Astronomy in Bath which is dedicated to the many achievements of William and Caroline Herschel. Apart from family memorabilia, the museum boasts a collection of telescopes, planetaria and globes. After a long day of thought-provoking presentations, delegates were also able to relax on Wednesday evening at a 
reception hosted by Sophia Centre Press where they were amply plied with drinks and finger food and had the opportunity to browse the bookstall. The occasion was to mark the launch of three new key texts in cultural astronomy. Firstly, there were the two Sophia Centre Press volumes: Heavenly Discourses edited by Nicholas Campion (Lampeter, 2016) and The Materiality of the Sky, Proceedings of the $22^{\text {nd }}$ Annual SEAC Conference, 2014 (Lampeter, 2016), edited by Fabio Silva, Kim Malville, Tore Lomsdalen and Frank Ventura. Valerie Hall of Equinox Publishing Ltd was also on hand for the launch of The Imagined Sky (Sheffield, 2016), edited by Darrelyn Gunzburg, and to promote the Journal of Skyscape Archaeology, edited by Fabio Silva and Liz Henty.

On Thursday morning two optional excursions were offered to delegates. The first was a tour of Bath Abbey with architectural historian, writer, and Keeper of the Fabric at Bristol Cathedral, Jon Cannon The original building of the 1090s was one and a half times more extensive than its rebuild, begun in the 1480s and completed after the Reformation under the vision of Oliver King, bishop of Bath and Wells in 1500. The medieval abbey came alive once more with Jon's narrative. The second excursion was a trip to Stonehenge organised by Lionel Sims, for those who wished to witness sunrise at this iconic British monument. Because our access to the monument was approved by English Heritage for access at dawn, delegates had the unprecedented and no longer allowed privilege of entering the stone circle. Lionel has a deep understanding of the site's monumental landscape and history and accordingly, his onsite narratives and quizzes entertained and challenged his audience. It was hailed as an unforgettable and magical experience. Lionel also organised a tour to the Avebury Neolithic monuments about 20 miles north of Stonehenge, taking in Silbury Hill, the largest prehistoric mound in Europe, and the Avebury Stone Circle.

At the Annual General Meeting of SEAC, President Michael Rappenglück presented the Fifth Carlos Jaschek Award to Fabio Silva, the youngest recipient in SEAC's history, to fond and warm applause, as all present were well aware of the outstanding contribution he is making to the field of cultural astronomy.

\section{Theory and method in the study of Cultural Astronomy}

The conference organisers decided to highlight the importance of theory and method, as reflected in its title, and specifically asked contributors to acknowledge this both in their abstracts and presentations. Furthermore, the programme itself was devised so that papers were grouped by the type 
of primary source used - archaeology, ethnography, images and music and texts and archives - and hence reflective of the range of sources available to cultural astronomy. It also provided for some interesting discussions that linked papers presented in different sessions. Given the breadth of the conference theme, a decision was made to publish two sets of conference proceedings. General papers and case studies are included in this Culture and Cosmos volume, while theory and method papers will appear in a specially themed issue of the Journal of Skyscape Archaeology, due to be published in December 2017. These proceedings can only give a flavour of the many varied and inspiring presentations, co-chaired by Nicholas Campion and Lionel Sims and other members of the organising committee and sadly cannot reproduce the warmth of meeting old and new friends, the often spectacular PowerPoint presentations, the posters, and the subsequent panel discussions. Nevertheless, we hope our selections below are enjoyable.

\section{Archaeology}

The archaeology papers cover a wide geographical span from sites in England and Scotland to those further afield in Europe, Jordan and the Americas. In their paper entitled 'Through the Gloomy Vale: Underworld Alignments at Stonehenge', Lionel Sims and David Fisher compare and test three interpretative explanatory design models for the Neolithic/Early Bronze Age palisade in the Stonehenge monument complex. Each model independently attests to there being dual design properties in some Neolithic and Bronze Age monuments as in the use of wood and stone, the mirror-imaging of landscape setting or, as in the case of this paper, a diacritical model involving materiality, landscape and lunar-solar alignments. Artefacts found within the Stonehenge monumental landscape are investigated by Claude Maumené in 'The Bush Barrow and Clandon Barrow Gold Lozenges and the Upton Lovell Golden Button: A Possible Calendrical Interpretation'. These decorative objects were most frequently thought to be ornamental breastplates designed to show the high-level political or religious status of the wearers, but the author proposes that they were crafted to facilitate counting, memorisation and transmission of the numbers of days of one or several synodic cycles of Venus, Mars and Jupiter, in agreement with a number of Lunar and Solar cycles. Additionally, the author notes that the symbolic lozenge shape associated with fertility and fecundity appeared in many of the cultural areas of ancient Europe. Further north in Inverness-shire in Scotland, J. Anna Estaroth conducts new research at the Early Bronze Age cairns at 
Balnuaran of Clava in 'Clava Cairns, Midwinter Sunset and the Minor Lunar Limit'. New alignments are investigated in order to verify skyscape phenomena and integrate them with previous academic research but her investigation of the importance of seasonal alterations in light and darkness leads to a new interpretation of these monuments.

Continuing the focus on cairns, Marianna P. Ridderstad, in 'Orientations of Late Neolithic to Bronze Age and Iron Age Long Cairns in Coastal Finland', analyses the orientations, landscape character and typology of 138 long cairns in coastal Finland. Importantly, she argues for there being cultural continuity between the Neolithic and Middle Bronze Age societies. Additionally, Ridderstad offers the idea that outside cultural influences, possibly connected to central ideologies of the Nordic Bronze Age, were a possible reason to explain the Type 2 ship-formed cairns encountered in the Ostrobothnia region. By combining micro and mesoscale analyses, A. César González García, Felipe Criado-Boado and Benito Vilas Estévez summarise current work exploring the 'Megalithic Skyscapes in Galicia'. They look at two unique passage graves - Dombate and Forno dos Mouros - as well as two megalithic clusters - Barbanza and Leboreiro - in search of patterns that go beyond the orientation of their entrances. Illumination effects, inter-visibility and the relation between monument and landscape are explored, leading to the first tentative glimpses of the Neolithic cosmology of Galicia. In 'Different Approaches to Cosmology in Archaeology and Their Application to Maltese Prehistory', Tore Lomsdalen outlines the different ways archaeologists have engaged with notions of cosmology and worldview. He explains how specific approaches, such as Site Catchment Analysis, Fragmentation, Access Analysis and the Archaeology of Death for example, can be combined with archaeoastronomical research, to provide a more holistic picture of meaning, using Maltese sites as examples. In their chapter 'Petra revisited: an astronomical approach to the Nabataean cultic calendar', Juan Antonio Belmonte and A. César González García also use a multi-source approach to gain insights into the Nabataean calendar. Their work indicates the importance of the winter solstice and a link between this period of the solar cycle with festivals and associated pilgrimages dedicated to the main deities of that time.

Four of the archaeology papers draw on the variety of New World cultural expressions of astronomy, from the American Southwest to the Inca World. In 'Investigation of Solstice Horizon Interactions at Chacoan Monumental Architecture', Andrew M. Munro, Tony Hull, J. McKim Malville, F. Joan Mathien and Cherilynn Morrow explore the Chacoan 
Great Houses of the American Southwest. Their approach was to look at them diachronically, seeking changes in the number of solstice foresights in the horizon across multiple time periods. They observe a significant rise during the Late Bonito phase, which adds weight to the argument for celestially-adept centralised leadership and/or a religious revival following the severe drought of the 1090s CE, illustrating how the skyscape could be appropriated for political and religious purposes. Photographs are usually a feature of any archaeological paper but J. McKim Malville and John L. Ninnemann demonstrate how they can be an important research tool in their paper 'Archaeoastronomy and Cultural Astronomy as Scientific Disciplines: Falsifiability and Photo Documentation'. They recognise that digital photography is one of several tools in the field that bridges the gap between observation, essential documentation, and a search for meaning and present case studies to back up their arguments. Steven R. Gullberg and J. McKim Malville look at the role of light hierophanies in caves in the Inca world. In 'Caves, Liminality, and the Sun in the Inca World' they report on fieldwork in a great number of caves, the results of which reveal a widespread interest in combining solar illuminations on key dates with artificially altered sections or features of the cave structures, such as steps or niches. The authors suggest that these caves were specifically chosen because sunlight already entered into them, and it is likely that the caves were perceived to be animated by the interaction of sunlight, water and darkness. In 'Rethinking Nahualac, Iztaccíhuatl, Mexico: Between Animism to Analogism in Mesoamerican Archaeoastronomy', Stanisław Iwaniszewski addresses the ritual and worldview of a culture that created a rectangular stone sanctuary on the western slopes of a prominent volcano in Central Mexico. Using the claimed astronomical alignments of the site, Iwaniszewski explains how Postclassic societies in Central Mexico conceptualised their relationship with the environment.

\section{Ethnography}

The use of ethnography, history and folklore adds another dimension to understanding cultural practices related to the sky, as the papers in this section demonstrate. Taking an historical and ethnographical approach Nasser B. Ayash presents his paper 'Evolution of Arabic Astronomy in Relation with the Translation Movement in the Early Abbasid Era'. In this work Ayash draws a thread from the Greek and Persian perceptions of the sky to its becoming embedded into the pre-Islamic astrological notions of Anwa and Lunar Mansions and, as a result, the Greek Uranography 
became a part of the foundations of the astronomy of the Abbasid era of the mid-eight to mid-ninth century CE.

Roslyn M. Frank has been researching the Basque stone octagons for nearly forty years and in her paper 'Metrology, Memory and Long-Term Landscape Inhabitation: Evidence for the Septarian Package on the Atlantic Façade' she brings new insights to this field. She examines the possible association of the Septarian Package with agro-pastoral practices and shows how its metrological diffusion can shed light on the cultural conceptualisations and practices that might have been associated with megalithic structures found along the Atlantic façade.

\section{Images}

Astronomical images seem to mirror the emphasis of the sky in many cultures, examples of which include rock art, petroglyphs, cup-marks and so on. Yet the papers in our 'Images' section show that this field can be imaginative, far-reaching and diverse enough to include virtual landscapes and skyscapes, stained glass windows and frescos. Georg Zotti, Florian Schaukowitsch and Michael Wimmer report on the creation of 'The Skyscape Planetarium', a visual installation at the MAMUZ museum for prehistory in Austria. The exhibition draws on results of the Stonehenge Hidden Landscapes Project, and includes a huge curved screen upon which a Stellarium simulation is projected, virtually recreating the experience of standing within the stone circle and looking out into the surrounding landscape and skyscape. The authors describe the planning and implementation of this innovative installation and outreach experience. In her paper 'Edward Burne-Jones's The Planets: Luna, A Celestial Sphere', Liana De Girolami Cheney examines how this Pre-Raphaelite artist became fascinated with, and inspired by, astronomy and created themed stained-glass windows in a body of work known as the Planets cycle. Concentrating on Luna, Cheney first discusses the history of the artistic commission and then explains the its cultural sources. In 'An examination of the images of the Sun and the Moon in the Visoki Dečani monastery in Kosovo', Dragana Van de moortel-Ilić contextualises the the tear-shaped images of the Sun and the Moon framing The Crucifixion of Christ fresco in the Visoki Dečani monastery in Kosovo. By placing these images into a cultural and contemporary cosmological context, she concludes that these personifications of the Sun and the Moon may be explained by the synergy of Hellenistic and Christian thought. 


\section{Acknowledgements}

The conference, and this volume, would not have come to fruition without the help of the Sophia Centre for the MA in Cultural Astronomy located at the University of Wales Trinity Saint David, the organising committee, the reviewing committee, and a dedicated band of volunteers, so our grateful thanks must go to the following:

Local Organising Committee: Nicholas Campion, Lionel Sims, Pamela Armstrong, Bernadette Brady, Frances Clynes, Darrelyn Gunzburg, Liz Henty, Frank Prendergast and Fabio Silva. Additional Reviewing Committee: John Steele, Emilia Pásztor, Kim Malville, Stanislaw Iwaniszewski, Juan Antonio Belmonte and Michael Rappenglück. Conference front desk and refreshments: Jennifer Fleming. Book Stall: Jennifer Zahrt. Conference volunteers: Ada Blair, Ilaria Cristofaro, Karine Dilanyan, Anna Estaroth, Morag Feeney-Beaton, Stavroula Konstantopoulou, Tore Lomsdalen, Chris Mitchell, Hanne Skagen, Melanie Sticker and Kathleen White.

Liz Henty, Bernadette Brady, Darrelyn Gunzburg, Frank Prendergast and Fabio Silva 

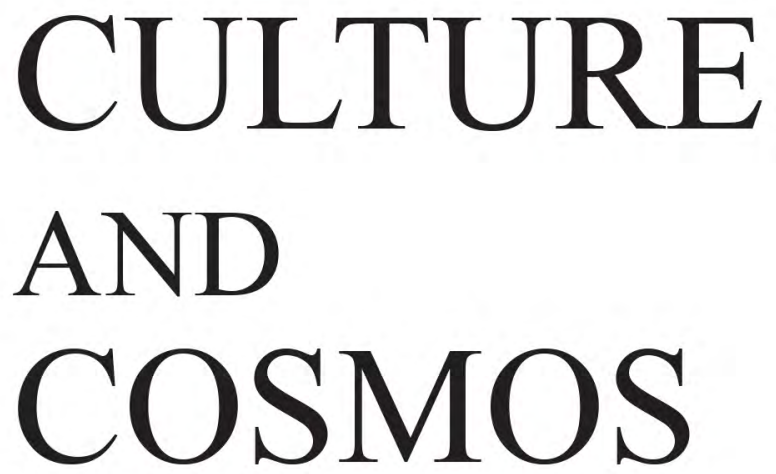

A Journal of the History of Astrology and Cultural Astronomy

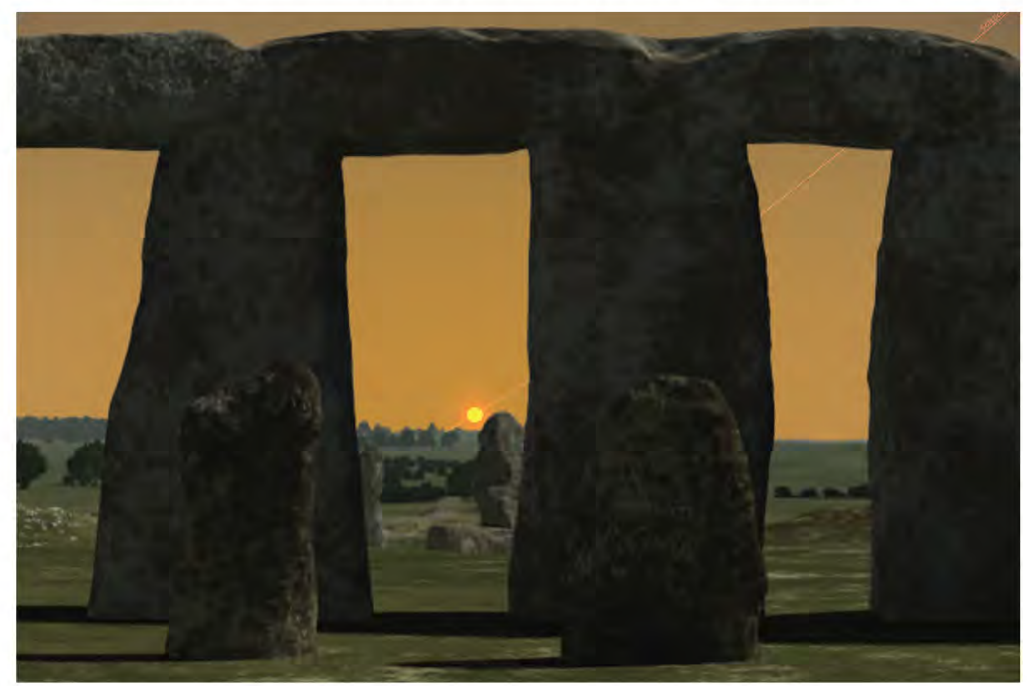

The Marriage of Astronomy and Culture:

\section{Theory and Method in the Study of \\ Cultural Astronomy}

Papers from the 2016 SEAC Conference

Edited by Liz Henty, Bernadette Brady, Darrelyn Gunzburg,

Frank Prendergast and Fabio Silva

Volume 21 Number 1 and 2

Spring/Summer and Autumn/Winter 2017 